\title{
PREDIKSI TINGGI MUKA AIR BENDUNGAN RIAM KANAN MENGGUNAKAN ADAPTIVE NEURO FUZZY INFERENCE SYSTEM
}

\author{
Yusri Ikhwani \\ Fakultas Teknologi Informasi \\ Universitas Islam Kalimantan Muhammad Arsyad Al Banjari Banjarmasin \\ Email : yusri.ikhwani@gmail.com
}

\begin{abstract}
ABSTRAK
Bendungan riam kanan yang berada kabupaten banjar ialah salah satu waduk terbesar di kalimantan selatan yang ada di aranio, kabupaten banjar. Waduk buatan yang dalam pembangunannya memakan waktu selama 10 tahun ini dibangun membendung 8 sungai yang bersumber dari Pegunungan Meratus. Tujuan utama dibangunnya waduk riam kanan adalah untuk membangun pembangkit listrik tenaga air untuk daerah kalimantan selatan dan sekitarnya.

Tujuan penelitian ini ialah untuk memprediksi tinggi muka air bendungan riam kanan menggunakan metode Adaptive Neuro Fuzzy Inference System (ANFIS) agar dapat bermanfaat dalam kebijakan strategis ketahanan energi khususnya ketahanan pangan dan energi listrik, khususnya ketersediaan air untuk saluran irigasi.

Perkiraan prediksi ini menggunakan data tinggi muka air bendungan riam kanan dari tahun 2009 sampai dengan 2015 yang didapatkan dari PLTU riam kanan provinsi kalimantan selatan. Prosedur memprediksi diawali dengan melakukan proses pembagian data, yaitu menjadi data pelatihan dan data pengujian. Setelah itu dilakukan penentuan variabelvariabel pendukung input yang memberikan korelasi cukup signifikan terhadap variabel output. Serelah itu melakukan proses pengujian dengan membandingkan 2 membership function untuk menentukan yang mana memiliki tingkat akurasi yang baik dan nilai error yang rendah dalam memprediksi tinggi muka air bendungan riam kanan.

Hasilnya ialah prediksi tinggi muka air bendungan riam kanan menggunakan metode Adaptive Neuro Fuzzy Inference System (ANFIS) dengan membandingkan 2 membership function dengan tingkat keakuratan menghasilkan nilai RMSE 0,010065 pada membership function Bell
\end{abstract}

Kata kunci: bendungan riam kanan, anfis, prediksi, tinggi muka air, membership fungtion

\section{PENDAHULUAN}

Bendungan Riam Kanan di

Kabupaten Banjar adalah salah satu waduk terbesar di Kalimantan Selatan yang ada di Aranio, kabupaten Banjar. Waduk buatan yang dalam pembangunannya memakan waktu selama 10 tahun ini dibangun membendung 8 sungai yang bersumber dari Pegunungan Meratus.

Pembangunan Waduk Riam Kanan memiliki tujuan utama sebagai
Pembangkit Listrik Tenaga Air yang didistribusikan untuk wilayah Kalimantan Selatan dan diresmikan oleh Presiden Suharto pada tahun 1973.

Keberadaan air sangat penting dipermukaan bumi ini, air tidak hanya sebagai memenuhi kebutuhan minum manusia dan mahluk hidup yang lainnya. Air juga sangat berguna untuk memenuhi kebutuhan energi listrik, pertanian, transportasi, wisata dll. Sangat pentingnya 
air sehingga manusia berusaha untuk tetap menjaga ketersediaannya air. Berbagai cara untuk menjaga tersebut seperti membuat bendungan, bendung, reboisasi dll. Terpeliharanya Daerah Aliran Sungai (PP No 37 Tahun2012 2012) merupakan sumber penting terjaganya ketersedian air untuk Bendungan Riam Kanan.

Perubahan iklim yang terjadi menyebabkan Tinggi Muka Air Bendungan Riam Kanan di Kabupaten Banjar Provinsi Kalimantan Selatan terjadi penurunan tinggi muka air. Perubahan tinggi muka air ini menjadi kajian untuk mengetahui algoritma apa yang baik untuk mengetahui prediksi tinggi muka air.

Metode yang digunakan untuk melakukan pengambilan data dalam penelitian ini adalah dengan melakukan pengukuran tinggi muka air pada Bendungan Riam Kanan. Pada penelitain ini digunakan metode Adaptive Neuro Fuzzy Inference System (ANFIS) dengan membership function.

\section{RUMUSAN MASALAH}

Berdasarkan latar belakang di atas, maka rumusan masalah pada penelitian ini ialah bagaimana memprediksi Tinggi Muka Air Bendungan Riam Kanan menggunakan metode Adaptive Neuro Fuzzy Inference System (ANFIS) dengan membandingkan beberapa membership function.

\section{TUJUAN PENELITIAN}

Tujuan dari penelitian ini ialah merancang dan menghasilkan perkiraan/prediksi tinggi muka air Bendungan Riam Kanan menggunakan metode Adaptive Neuro Fuzzy Inference System (ANFIS) dengan membandingkan beberapa membership function dengan menggunakan software Matlab2014b sebagai software dalam mengolah data.

\section{METODE PENELITIAN}

Metode yang digunakan ialah metode eksperimen, dengan tahapan sebagai berikut :

1. Pengolahan Data

Penelitian ini memakai data Tinggi Muka Air pada Bendungan Riam Kanan, yang didapatkan dari PLTU Riam Kanan Provinsi Kalimantan Selatan.

Data yang dibutuhkan dalam penelitian ini adalah:

- Data Primer

Data primer yang digunakan ialah data pengukuran Tinggi Muka Air Bendungan Riam Kanan yang di ukur sebanyak 3 kali dalam sehari.

- Data Sekunder

Data Sekunder adalah data primer yang di cari nilai rata-rata harian tinggi muka air Bendungan Riam Kanan. Data Sekunder ini digunakan sebagai data untuk memprediksi tinggi muka air Bendungan Riam Kanan menggunakan metode Adaptive Neuro Fuzzy Inference System (ANFIS).

Penelitian ini memakai data Tinggi Muka Air Bendungan Riam Kanan dari tahun 2011 sampai dengan 2014 yang didapatkan dari PLTU Riam Kanan Provinsi Kalimantan Selatan.

2. Pengolahan Data

Data yang diperoleh dari PLTU Riam Kanan Provinsi Kalimantan Selatan berupa data dalam bentuk file excel yang masih nerupa data mentah terdiri numerik. Data yang digunakan ialah data dengan atribut tinggi muka air harian mulai dari tahun 2009 sampai dengan tahun 2015. Data tinggi muka air harian dari tahun 2009 sampai tahun 2014 dijadikan sebagai data training dan data tinggi muka air harian tahun 2015 dijadikan sebagai data testing. Tiap baris data adalah data tinggi muka air setiap hari, untuk data training sebanyak 2190 sedangkan untuk data testing sebanyak 212 baris. 


\section{PT PLN (PERSERO) WKSKT
SEKTOR BARITO}

\begin{tabular}{|c|c|c|c|c|c|c|c|c|c|c|}
\hline TGLBULAN & 2009 & 2010 & 2011 & 2012 & 2013 & 2014 & 2015 & KETERANGAN & BATAS ATAS & BATAS BAWAH \\
\hline 01vanery & 59980 & 55550 & 59520 & 57.740 & 56160 & 55.870 & 57.100 & & 55.330 & 53.13 \\
\hline Q2vanery & 59900 & 55650 & 59480 & 57.860 & 56410 & 55.900 & 57270 & & 55.43 & 53.15 \\
\hline O3.Janery & 59960 & 55810 & 59430 & 57.925 & 56450 & 55.940 & 57.400 & & 55.53 & 53.25 \\
\hline O4.vanery & 59940 & 55850 & 59420 & 57.945 & 56490 & 55.970 & 57.485 & Terjadi Pelinpasan Januari 99 & 55.63 & 53.35 \\
\hline 05.vanery & 59900 & 55800 & 59400 & 57.940 & 56500 & 56.010 & 57500 & sda & 55.73 & 53.45 \\
\hline 06.vanery & 59965 & 55900 & 59360 & 57.960 & 56700 & 56.000 & 57650 & sda & 55.83 & 53.55 \\
\hline 07vanery & 59800 & 55915 & 59300 & 57.970 & 56750 & 55990 & 57720 & sda & 55.93 & 53.65 \\
\hline Obvanery & 59980 & 56070 & 59206 & 57980 & 56800 & 55.960 & 57750 & sda & 58.03 & 53.75 \\
\hline Og.vanery & 59980 & 56025 & 59300 & 57980 & 56900 & 55.950 & 57750 & sda & 58.13 & 53.85 \\
\hline 10.Janery & 60010 & 56090 & 59280 & 58030 & 56950 & 55.940 & 57760 & sda & 58.23 & 53.95 \\
\hline 11. vanery & 60220 & 56090 & 59260 & 58050 & 56965 & 55.930 & 57800 & sda & 58.33 & 54.05 \\
\hline 12. vanery & 60325 & 56070 & 59240 & 58040 & 56990 & 55.905 & 57860 & sda & 58.43 & 54.15 \\
\hline 13.vanery & 60410 & 56096 & 59215 & 58040 & 56980 & 55.865 & 58800 & sda & 58.53 & 54.25 \\
\hline 14.vanery & 60480 & 56.110 & 59200 & 58015 & 56970 & 55.860 & 5790 & sda & 58.63 & 54.35 \\
\hline 15.vanery & 60570 & 56210 & 59220 & 58005 & 56990 & 55.880 & 58030 & sda & 58.73 & 54.45 \\
\hline 16.vanery & 60655 & 56240 & 59250 & 57.980 & 57.000 & 55.960 & 58.130 & sda & 58.83 & 54.55 \\
\hline 17. vanuery & 60650 & 56220 & 59225 & 57.945 & 57.020 & 55940 & 58.190 & sda & 58.93 & 54.65 \\
\hline 18.vanery & 60715 & 56200 & 59200 & 57.960 & 57.010 & 55.960 & 58230 & sda & 57.03 & 54.75 \\
\hline 19.janery & 60760 & 56250 & 59260 & 57.920 & 56990 & 55.920 & 58200 & sda & 57.13 & 54.85 \\
\hline 20.vanuery & 60755 & 56250 & 59240 & 57.890 & 57.000 & 55.910 & 58300 & & 57.23 & 54.95 \\
\hline 21. vanuery & 60700 & 56230 & 59210 & 57.860 & 56965 & 55.800 & 58360 & & 57.33 & 55.05 \\
\hline 22. vanery & 60670 & 56230 & 59.190 & 57.850 & 56950 & 55.850 & 58380 & & 57.43 & 55.15 \\
\hline 23.vanery & 60610 & 56.190 & 59.175 & 57.830 & 56950 & 55.820 & 58380 & & 57.53 & 55.25 \\
\hline 24.vanuary & 60570 & 56150 & 59.175 & 57.815 & 56950 & 55.800 & 58500 & & 57.63 & 55.35 \\
\hline 25.Janery & 60520 & 56.130 & 59.175 & 57.780 & 56940 & 55.770 & 58740 & & 57.73 & 55.45 \\
\hline 26.Januery & 60625 & 56.115 & 59.175 & 57.730 & 56940 & 55.750 & 58790 & & 57.83 & 55.55 \\
\hline 27.vanuery & 60580 & 56065 & 59015 & 57.675 & 56940 & 55.720 & 58800 & & 57.93 & 55.65 \\
\hline 28.vanery & 60515 & 56.110 & 58980 & 57.620 & 56960 & 55.655 & 58800 & & 58.03 & 55.75 \\
\hline 20.vanuery & 60450 & 56.110 & 58940 & 57.580 & 56980 & 55.620 & 58800 & & 58.13 & 55.85 \\
\hline 30-vanuery & 60420 & 56.150 & 58950 & 57.500 & 56990 & 55.570 & 58860 & & 58.23 & 55.95 \\
\hline 31. vanuary & 60355 & 56250 & 58960 & 57.630 & 57.020 & 55.540 & 58920 & & 58.33 & 56.05 \\
\hline
\end{tabular}

\section{Gambar Data Awal}

\section{Metode}

Bererapa metode yang digunakan dalam penelitaan untuk memprediksi tinggi muka air beraneka ragam namun belum diketahui metode manakah yang memiliki kinerja yang baik dan menghasilkan akurasi yang akurat, sehingga masing-masing metode / algoritma diujikan untuk mengetahui hasilnya. Metode yang di usulkan dalam penelitian ini ialah metode Adaptive Neuro Fuzzy Inference System (ANFIS) dengan membandingkan beberapa membership function untuk dapat memprediksi data rentet waktu yang digunakan dalam memproses tinggi muka air. Dalam mengimplementasikan metode ini digunakanlah perangkat tambahan/ software yaitu Matlab.
4. Eksperimen dan Pengujian

Algoritma yang telah dikembangkan dalam penelitian ini akan diterapkan pada data tinggi muka air 2009-2015 pada Bendungan Riam Kanan Kabupaten Banjar melalui suatu model simulasi. Data 2009-2014 akan dipergunakan sebagai data training dan data 2015 akan digunakan sebagai data testing.

Pengukuran kinerja dilakukan dengan menghitung rata-rata error yang terjadi melalui besaran Root Mean Square Error (RMSE). Semakin kecil nilai dari masing-masing parameter kinerja ini menyatakan semakin dekat nilai prediksi dengan nilai sebenarnya. Dengan demikian dapat diketahui algoritma yang lebih akurat. 


\section{Evaluasi dan Validasi Hasil}

Evaluasi dilakukan dengan menganalisis dan membandingkan hasil prediksi tinggi muka air dengan metode ANFIS. Pengukuran kinerja dilakukan dengan menghitung rata-rata error yang terjadi melalui besaran Root Mean Square Error (RMSE). Semakin kecil nilai dari masing-masing parameter kinerja ini menyatakan semakin dekat nilai prediksi dengan nilai sebenarnya.

6. Kerangka Pemikiran

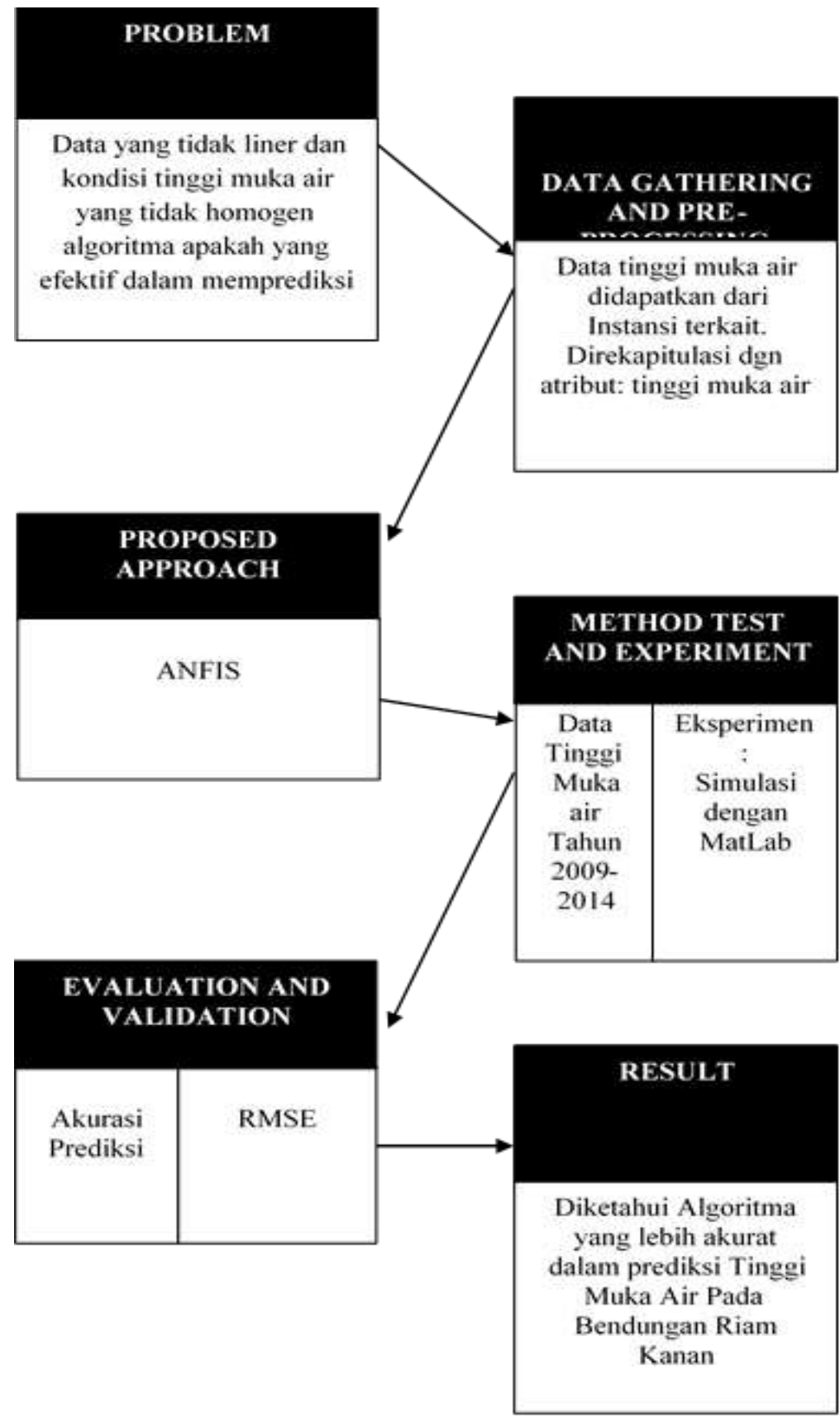




\section{ANALISIS HASIL DAN PEMBAHASAN}

Metode

ANFIS

dengan membandingkan beberapa membership function yang diusulkan dalam penelitian ini akan diterapkan pada data Tinggi Muka Air Bendungan Riam Kanan di Kabupaten Banjar Provinsi Kalimantan Selatan tahun 2009-2015 Bendungan Riam Kanan di Kabupaten Banjar Provinsi Kalimatan Selatan.

\section{- Gambar Pengujian dengan menggunakan membership function bell}

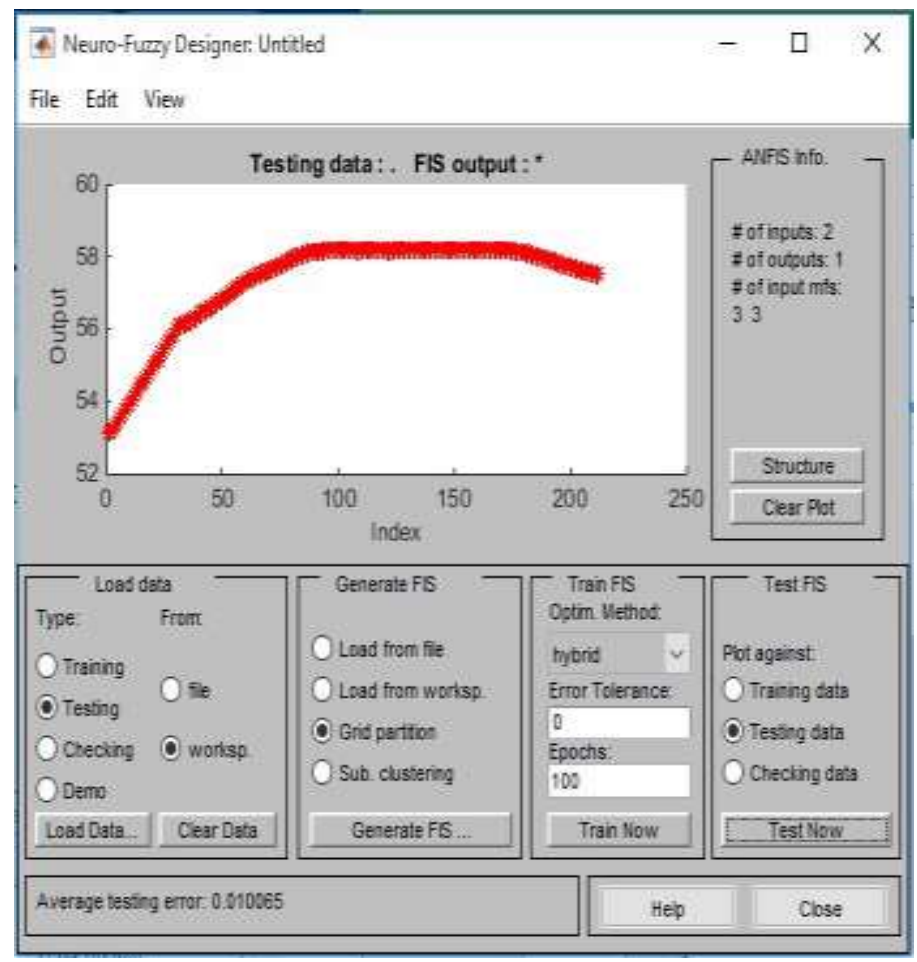

Gambar di atas merupakan hasil pengujian prakiraan tinggi mata air dengan menggunakan membership function Bell dengan hasil RMSE yang di dapat ialah 0,010065

- Gambar Pengujian dengan menggunakan membership function Trimf

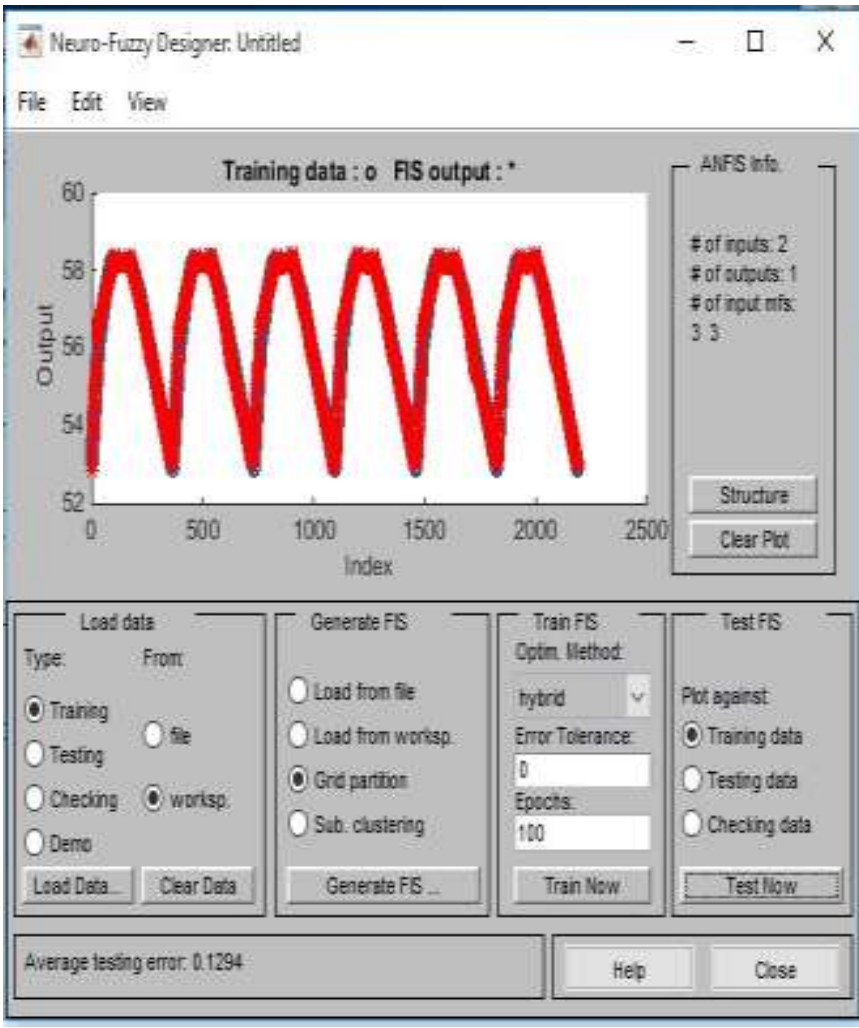

Gambar di atas merupakan hasil pengujian prakiraan tinggi mata air dengan menggunakan membership function Trimf dengan hasil RMSE yang di dapat ialah 0,1294

\section{- Gambar Rule dengan membership function bell}

Gambar dibawah ini adalah Hasil

Rule ANFIS membership function bell

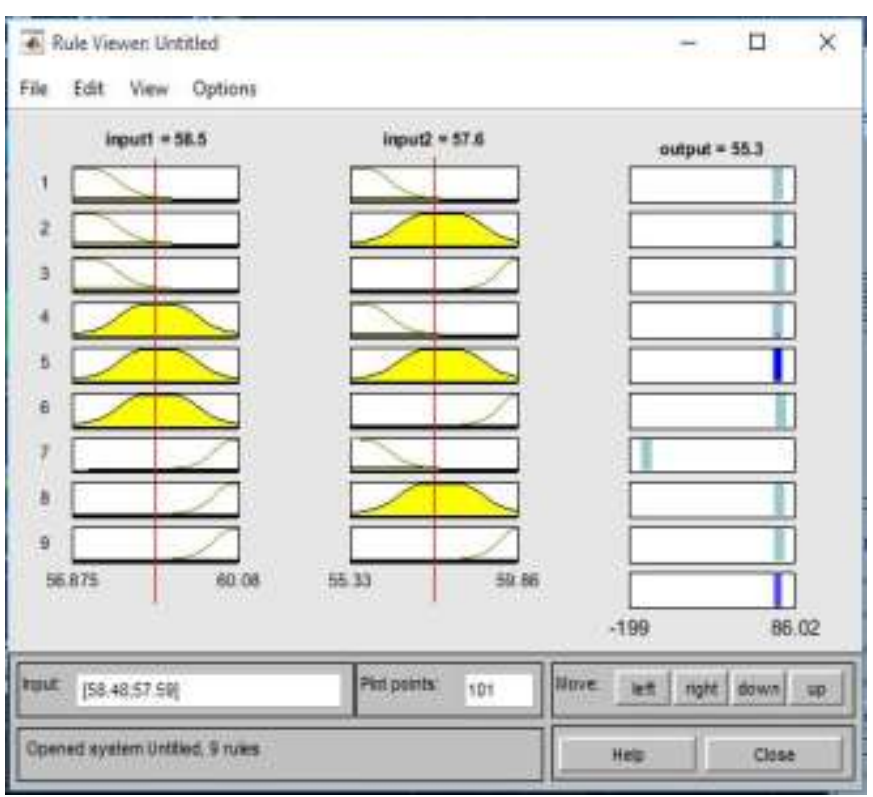


Hasil Arsitektur ANFIS dengan membership function bell yang didapat pada gambar dibawah ini :

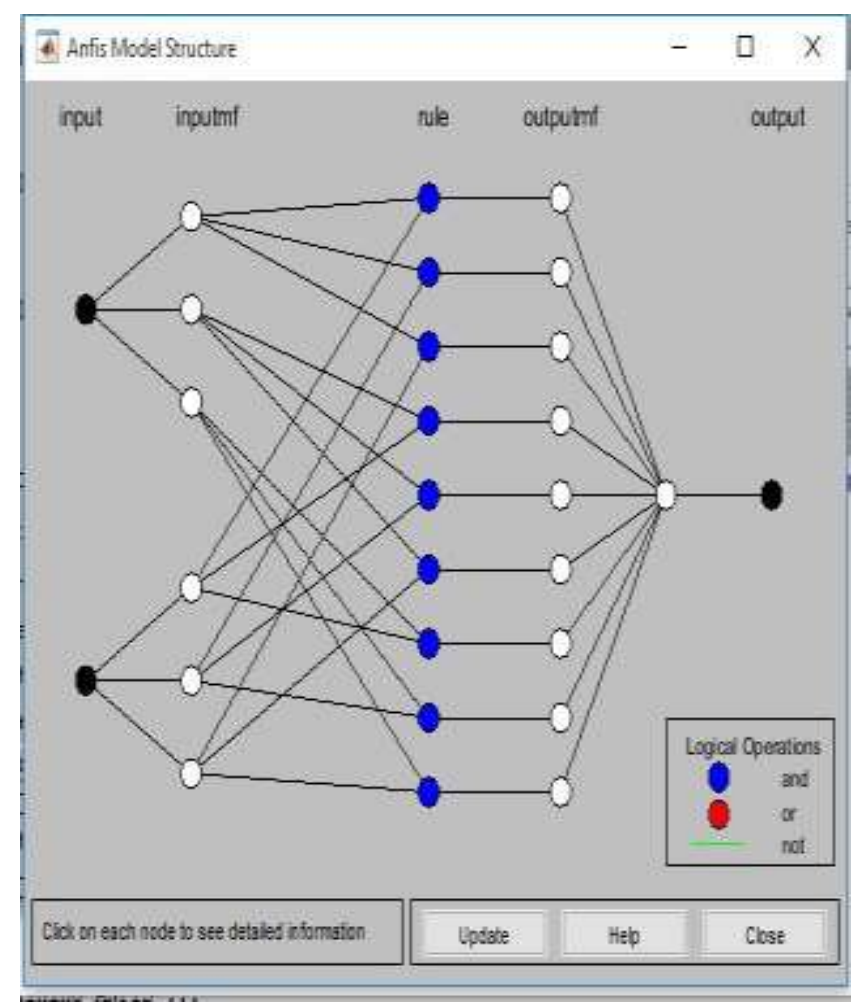

- Gambar Surface membership function bell

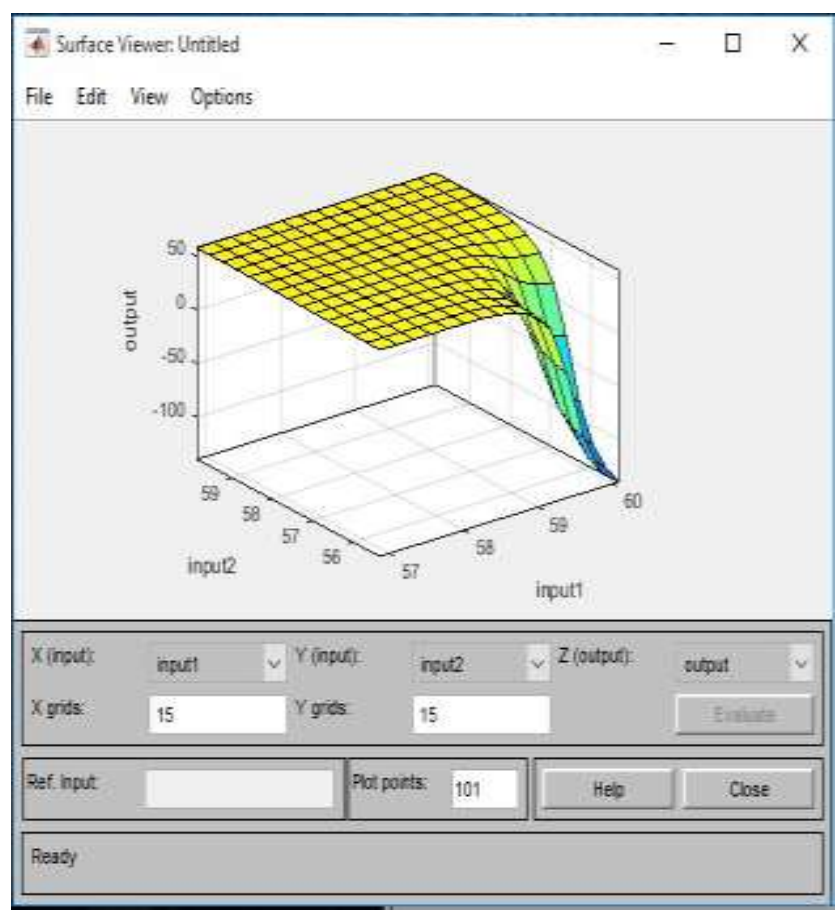

Tabel Evaluasi Hasil

\begin{tabular}{|c|c|c|c|c|c|}
\hline \multirow[b]{2}{*}{$\stackrel{\circ}{z}$} & \multirow[b]{2}{*}{ 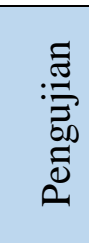 } & \multirow[b]{2}{*}{ 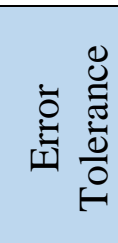 } & \multirow[b]{2}{*}{$\begin{array}{l}\text { 응 } \\
\text { ㅁ. } \\
\text { 되 }\end{array}$} & \multicolumn{2}{|c|}{ RMSE } \\
\hline & & & & $\begin{array}{l}\text { Members } \\
\text { hip } \\
\text { Function } \\
\text { Trimf }\end{array}$ & $\begin{array}{l}\text { Members } \\
\text { hip } \\
\text { Function } \\
\text { Bell }\end{array}$ \\
\hline 1 & P1 & 0,01 & 100 & 0,013868 & 0,010065 \\
\hline 2 & P3 & 0,03 & 100 & 0,1294 & 0,103 \\
\hline 3 & P5 & 0,13 & 50 & 0,99556 & 0,11315 \\
\hline 4 & P7 & 0,15 & 100 & 0,1298 & 0,11315 \\
\hline 5 & P13 & 0,9 & 9 & 51,0607 & 56,4766 \\
\hline 6 & $\mathrm{P} 18$ & 0,6 & 6 & 6,5604 & 1,3563 \\
\hline
\end{tabular}

Dari hasil evaluasi analisa diatas, maka dapat disimpulkan bahwa pengujian P1 yang memiliki nilai RMSE 0,010065 paling kecil untuk metode ANFIS dengan membership function bell dengan error tolerance 0,01 dan epoch 100.

\section{PENUTUP}

- Kesimpulan

Berdasarkan hasil penelitian dan pengukuran, penerapan metode Adaptive Neuro Fuzzy Inference System (ANFIS) dengan membandingkan beberapa membership function memiliki nilai lebih dalam proses prediksi dengan menggunakan data pendukung menghasilkan nilai RMSE 0,0100 sehingga menjadikan tingkat akurasi yang lebih baik dan dengan menambahkan membandingkan beberapa membership function menghasilkan akurasi yang berbeda.

Dengan demikian, adanya penerapan metode Adaptive Neuro Fuzzy Inference System (ANFIS) mampu memberikan solusi bagi petugas maupun instansi terkait, serta mampu menjadi alat prediksi dalam mengambil keputusan dalam bidang ketahanan energi khususnya energi listrik dan ketahanan pangan, kesedian air untuk saluran irigasi. 


\section{DAFTAR PUSTAKA}

[1] Adnan, R. et al., 2012. Artificial Neural Network Modelling and Flood Water Level Prediction Using Extended Kalman Filter., pp.23-25.

[2] Haldi Budiman, Yusri Ikhwani, M. Rasyidan. 2016. Prediksi Tinggi Muka Air Bendungan Riam Kanan Menggunakan Algoritma Cascade Neural Network. Banjarmasin

[3] Kamber, J.H. and M., 2006. Data Mining concepts and Techniques,

[4] Hall, C.\&, 2009. The Top Ten Algorithms in Data Mining,

[5] Kamber, J.H. and M., 2006. Data Mining concepts and Techniques,

[6] Kusumadewi, S., S. Hartati, 2006, Neuro Fuzzy Integrasi Sistem Fuzzy dan Jaringan Syaraf, Graha Ilmu, Yogyakarta

[7] Lilis Angraini, 2017. Anfis Dengan Membership Function Untuk Prediksi Curah Hujan Pada Data Rentet Waktu Multivariate, Banjarmasin

[8] Markidakis, Spyros et all.,1999, Metode dan Aplikasi Peramalan, Binarupa Aksara, Jakarta

[9] PP No 37 Tahun 2012, 2012. Peraturan Pemerintah Repuplik Indonesia Nomor 37 tahun 2012 tentang Pengelolaan daerah Aliran Sungai.

[10] Purwanto, E., C \& Logeswaran, R., 2011. Improved Adaptive NeuroFuzzy Inference System for HIV /
AIDS Time Series Prediction. , pp.113. 